\title{
Patellar Metastasis in Renal Cell Carcinoma: A Rare Presentation
}

\author{
Sahil Bambroo ${ }^{1}$ Thadi Mohan ${ }^{2}$ Keechilat Pavithran ${ }^{10}$ \\ ${ }^{1}$ Department of Medical Oncology, Amrita Institute of Medical \\ Sciences and Research Center, Amrita Viswa Vidyapeetham, Kochi, \\ Kerala, India \\ 2 Department of Orthopedics, Amrita Institute of Medical Sciences \\ and Research Center, Amrita Viswa Vidyapeetham, Kochi, Kerala, \\ Address for correspondence Keechilat Pavithran, MD, DM, FRCP, \\ Department of Medical Oncology, Amrita Institute of Medical \\ Sciences and Research Center, Kochi 682041, Kerala, India \\ (e-mail: drkpavithran@gmail.com).
} India

Ind J Med Paediatr Oncol 2021;42:577-578.

A 61-year-old male underwent right-sided nephrectomy for renal cell carcinoma in June 2009. Histopathology showed conventional renal cell carcinoma, clear cell type, right kidney Fuhrman's nuclear grade II. He was staged to have pT3c NO M0. In August 2018, he developed pulmonary metastasis (an irregular soft tissue lesion in the perihilar region of the right middle lobe) and nodal metastasis (multiple subcarinal and right hilar nodes). His IMDC (International Metastatic RCC Database Consortium) Risk Score was 0 . He was started on Pazopanib (due to cost considerations) and was on regular follow-up. After 13 months of treatment with pazopanib (October 2019), he presented with pain in the right knee. X-ray of the right knee showed a lytic lesion in the patella (-Fig. 1). MRI scan of the knee joint showed a well-defined, lobulated, altered marrow signal intensity lesion within the patella located superomedially. This lesion

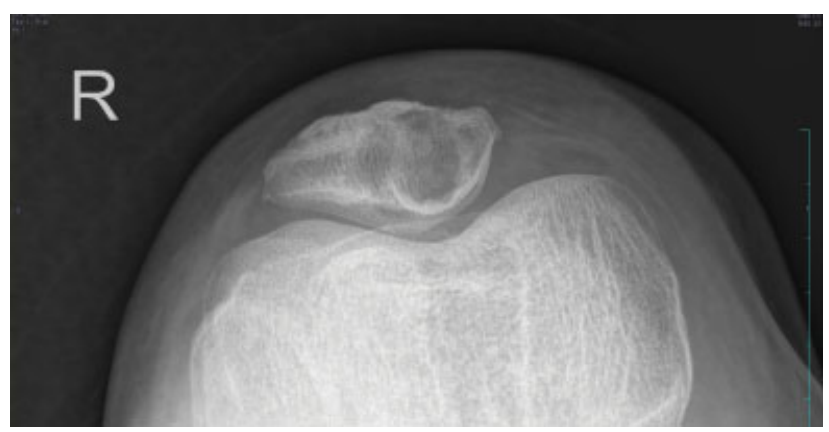

Fig. 1 X-ray skyline view showing a lytic lesion in the patella.

DOI https://doi.org/

10.1055/s-0041-1740139.

ISSN 0971-5851. was appearing hypointense on $\mathrm{T} 1$ and intensely bright on $\mathrm{T} 2$ images. Restaging was not done as he did not have any other symptoms. Routine blood parameters were normal.

He underwent curettage and bone cement application (-Fig.2). Histopathology from the right patellar lesion showed fibrocollagenous tissue with the presence of inflammatory cells and a neoplasm. The neoplasm was composed of clear cells

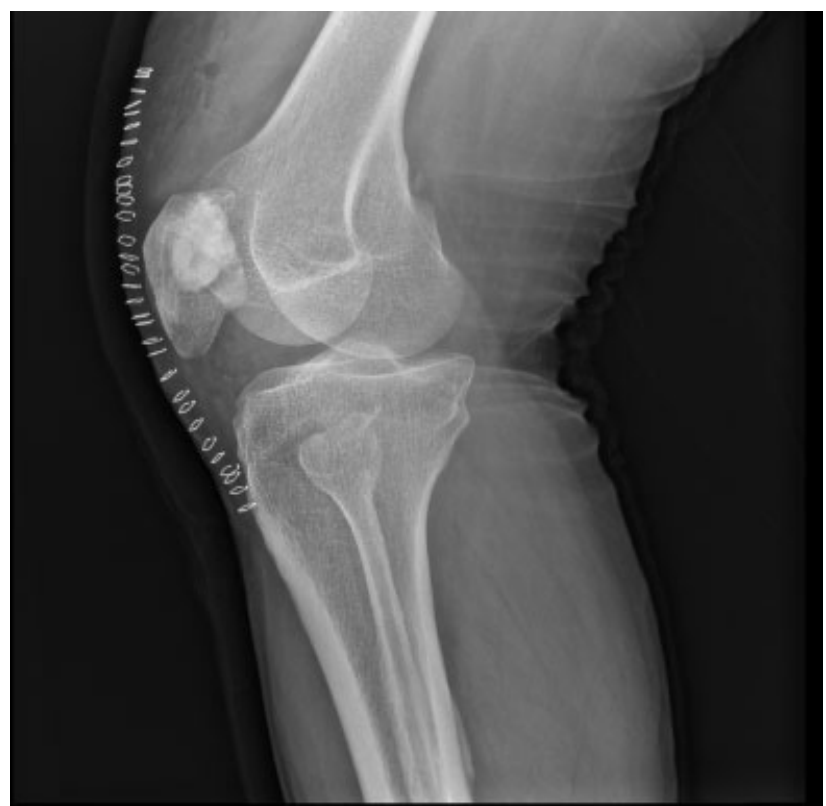

Fig. 2 X-ray lateral view showing lesion filled with bone cement.

(c) 2021. Indian Society of Medical and Paediatric Oncology. All rights reserved.

This is an open access article published by Thieme under the terms of the Creative Commons Attribution-NonDerivative-NonCommercial-License, permitting copying and reproduction so long as the original work is given appropriate credit. Contents may not be used for commercial purposes, or adapted, remixed, transformed or built upon. (https://creativecommons.org/ licenses/by-nc-nd/4.0/)

Thieme Medical and Scientific Publishers Pvt. Ltd., A-12, 2nd Floor, Sector 2, Noida-201301 UP, India 
arranged in nests. These clear cells were observed to be polygonal in shape and having a pale eosinophilic to clear cytoplasm and round to spindle-shaped hyperchromatic nuclei. Fibrovascular septae separated these nests. These findings were suggestive of metastatic clear cell carcinoma. He was given local radiation to the site with $20 \mathrm{~Gy}$ in five fractions, and pazopanib was continued. In January 2020, he became symptomatic with cerebral metastasis and was given whole-brain radiation for the same. He succumbed to his illness in November 2020.

Primary patellar tumors account for less than $1 \%$ of all bone tumors. Reports of metastatic lesions to the patella are even rarer. The rarity of patellar metastases is thought to be due to the patella's distal location and the relatively poor blood supply to the sesamoid bones. The most common primary tumor that usually metastasizes to the patella is lung carcinoma. Other metastasizing cancers are carcinomas of the breast, kidneys, esophagus, uterine cervix, cutaneous malignant melanoma, and head and neck. ${ }^{1}$

Fourteen percent of all patellar metastases were reported to arise from the kidneys in a case series. ${ }^{2}$ Knee pain is a common clinical manifestation and can be associated with trauma or pathological fracture. Surgery can be offered if no other evidence of metastasis is seen elsewhere. However, bony metastasis from renal cell carcinoma appears to behave similarly to primary bone disease. Some experts believe there is no survival advantage by performing a wide resec- tion in place of intralesional curettage and local stabilization. ${ }^{2}$ The use of radiotherapy and bisphosphonates has also been advocated.

\section{Declaration of Patient Consent}

The authors certify that they have obtained all appropriate patient consent forms. In the form, the patient(s) has/have given his/her/their consent for his/her/their images and other clinical information to be reported in the journal. The patients understand that their names and initials will not be published, and due efforts will be made to conceal their identity, but anonymity cannot be guaranteed.

Funding

None.

\section{Conflicts of Interest}

None declared.

\section{References}

1 Broomfield J, Ralte P, Morapudi S, Vasireddy N, Kershaw S. Anterior knee pain: an unusual presentation of renal cell carcinoma. J Surg Case Rep 2014;2014(03):rju018

2 Li G, Shan C, Sun R, et al. Patellar metastasis from primary tumor. Oncol Lett 2018;15(02):1389-1396 